\title{
Eliminating Lectures (and video lectures) in Large Introductory Materials Science and Engineering Courses: Large Gains in Student Learning
}

\author{
Prof. Steven M. Yalisove, University of Michigan
}

S. M. Yalisove obtained a PhD in Materials Science and Engineering at the University of Pennsylvania in 1986. After a post doc at Bell Laboratories, he joined the Michigan faculty in 1989. In 1996 he was a Fulbright scholar at the FOM institute in the Netherlands. He is currently the Associate Director of the Materials Laboratory at the Center for Ultrafast Optical Sciences at the University of Michigan. Yalisove's current research focuses on understanding the relationships between atomic structure and materials properties at surfaces and interfaces in a wide variety of material systems. He has made important contributions to the fields of surface science, thin film growth, evolution of thin film morphology, and most recently, the interaction of high intensity femtosecond laser pulses and materials. Ultrafast laser/material interaction is being studied in his group to understand the fundamental mechanisms which drive ablation and collateral damage. His work focuses on the modification and material removal processes in metals, semiconductors and ceramics as well as organic materials including graphene and carbon nanotubes. Yalisove uses a variety of characterization techniques including pump-probe ultrafast microscopy, femtosecond Laser Induced Breakdown Spectroscopy (fsLIBS), dual pulse LIBS, optical and scanning electron microscopy, transmission electron microscopy, and a variety of in-situ probes. Recently his group discovered a novel approach to nano and micro fluidic channel manufacturing using ultrafast lasers. Additionally, his group has been investigating the role that fs lasers can play in modification of interfaces for joining materials. A recent discovery of non-thermal point defect injection mechanisms (well below the melt threshold) offer a novel approach for diffusion bonding. His group is also studying interfacial morphological changes to increase surface of an interface as well as using still higher fluence to induce shock waves for mechanical bonding. Steven has also been very interested in educational pedagogies since 1996 when he was the first person at UM to use clickers. He was also the first person at UM to reject clickers. Almost 20 years later, he has, once again, embraced clicker technology now that he has eliminated lectures and has time in class for peer instruction.

\section{Dr. Shanna R. Daly, University of Michigan}




\title{
Eliminating Lectures (and video lectures) in Large Introductory Materials Science and Engineering Courses: Large Gains in Student Learning
}

\begin{abstract}
Lecturing to passive students has dominated engineering education despite numerous studies that suggest learning is more effective and deeper if active methods are used. The current study is an attempt to compare learning gains, as measured by exam scores, between the traditional lecture with some $(<10 \%)$ active learning activities and active learning class session where there was less than $10 \%$ of lecture. The work presented here will use the same 180 student class and the same instructor as both the control and intervention group. This introductory materials science and engineering class has been traditionally taught as three 50 minute lectures per week plus a 50 minute recitation. The experiment replaced one lecture a week with active learning activities and peer instruction while continuing to have traditional lectures the other two sessions per week.

These active learning sessions were augmented by a short online quiz that students were required to take. They were permitted to retake the quiz as many times as needed to earn the score they desired. These quizzes were based on the reading assignments.

An optional, short ( $<5 \mathrm{~min}$ ) video was produced each week to replace the only component of lecture that was deemed valuable, inspiration. These videos were not intended to transfer any information. Rather, these short documentary style videos featured a different faculty member and their graduate students each week, sharing their passion for their research in the material that we wanted our students to study.

Learning was assessed by tagging exam questions based on the presentation style (lecture or active learning) and comparing the data on two midterms and the final exam. All exams showed a significant difference in exam question score for concepts taught using active learning activities. For example, the final exam showed a 19\% difference in the median score on the active learning tagged questions versus the traditional lecture tagged questions.
\end{abstract}

The paper will include additional information on methodologies as well as additional results. We will also discuss our current approach to use the results from this study to guide revisions from the course, which is to eliminate lecture and focus on active engagement in problem solving during class time. 


\section{Introduction and results}

Research over the past 30 years has strongly suggested that very little learning happens during traditional lectures ${ }^{1}$. Yet, the vast majority of introductory University classes are still delivered using traditional lecture methods. This is certainly the case at the University of Michigan in the Materials Science and Engineering department. In fact, the vast majority of introduction to materials courses around the world are still taught with a traditional stand and deliver lecture mode.

Focus of research: Last year we performed an experiment to compare active learning methodologies to traditional lecture using what we believe was a novel approach. The study was an attempt to compare learning gains, as measured by exam scores, between the traditional lecture with some $(<10 \%)$ active learning activities and active learning class session where there was less than $10 \%$ of lecture. The research question was: Does reversing the proportion of lecture to active learning improve learning based on exam scores?

What we did: Our methodology was simple. We used the same class and instructor as both the control and the experimental samples by choosing to eliminate lecture in one third of the class sessions. The course was traditionally taught on Mondays, Wednesdays, and Fridays with a recitation on Thursdays that was run by graduate student instructors. A fixed syllabus has been used for many years and we kept that strictly in place. The same textbook and the same assessment tools (two midterms and a final) were used. What was changed was that on Wednesdays, no lecture was given. Instead, active learning methodologies were used to cover the main points that the lecture would have been focussed on. Instead of using the lecture to introduce material, we had the students read the book and take a short online quiz. We also provided a short, optional, video about the topic to be covered on Wednesdays. These videos were intended to inspire the students so that they would be more willing to read the book and study the material.

What we found: We measured the learning differences by tagging questions on the midterms and final as to whether they were based on the traditional lecture or the no-lecture approach. What we found was that the students scored between 10 and 19 points higher (the median) on exam questions that were based on material presented in active learning sessions compared to traditional lecture. 


\section{Background and motivation for the work}

The current course: The introductory MS\&E course is a critical course for our department. We teach roughly 800 students per year. There are typically three sections in the Fall and two sections in the Winter term. One third of the students take a Biomaterials flavored version of the course. All of our majors are required to take the course and it is our most important recruiting tool. The course is a traditional lecture class that meets 3 times a week with a recitation session run by a graduate student instructor. We have been using Callister's text for many years now and cover 17 chapters during the term. The Biomaterials version also uses Callister but only covers 16 chapters and adds supplemental readings.

Over the years, several improvements to the course have been made. Twenty years ago we formulated learning objectives for each lecture. We have a suite of live demonstrations that are used throughout the term. We have also experimented with audience response systems (well before Clickers showed up), in-class active learning activities, improved graphical presentation displays, returning to the chalk (white) board, use of video and animation, as well as using screencasts to augment the lecture. In all cases, the improvements have been worked into the lecture. Yet, it has been very difficult to tell whether or not these improvements have actually had an impact on student learning.

It was, however, clear the students responded very positively to the active learning methodologies. But, the instructors (including the author) found that it became hard to cover all of the material. Other researchers have suggested that syllabus pressure should be treated by asking the question "... would you rather have the students learn a smaller set of the material well than none of the entire set?" We have always rejected that suggestion. Instead, we asked whether we were asking the wrong question. Why not ask, "Is there any value to adding lecture to active learning methodologies?" If the answer was no, then, all of a sudden, there were 50 minutes per class period to run active learning activities. This was about the time needed to cover the 6 to 9 major topics that we typically cover in lecture. There is much evidence in the literature that suggests that students learn very little in traditional lecture. Perhaps they can be inspired, or sometimes they can just get confused. Hence, we thought it would be a good experiment to swap out one of the three class sessions per week and substitute active learning activities and do no lecturing at all. 


\section{Experimental design}

Our goal was to try and measure student learning gains buy completely replacing lecture with active learning activities. The experimental design needed to have a control and intervention groups. There are many difficulties with using multiple cohorts of students and instructors across sections. Instead, we used the same students and the same instructor but just alternated the intervention. We were constrained to offer exactly the same syllabus as all of the other sections of the course which was identical to what we have taught in previous years. The syllabus was broken down into lectures and there were already learning objectives written for each. Some topics take several lectures and other take a single lecture to cover. Class sessions were held on Mondays, Wednesdays and Fridays. Hence, we decided to eliminate lecture each Wednesday and use active learning methods exclusively that day. We gave traditional lecture with occasional active learning activities (about 10\% of each lecture) on Mondays and Fridays.

Class demographics: The class consisted of 40 Aerospace, 5 Computer Science, 55 Chemical Engineers, 1 Civil, 3 Electrical, 3 Engineering Physics, 3 Engineering First Year, 2

Environmental, 38 Industrial and Operational Engineering, 8 Materials Science and Engineering, 13 Nuclear Engineering, and 6 non engineering students. Of these, 58 were seniors, 65 were juniors, and 54 were sophomores (defined by number of credits earned - so some of the sophomores were actually first year and some of the juniors may have been second year, etc.). 40 of the students were women and 9 were underrepresented minorities. We did not break down the performance of any of the groups in this study.

Syllabus: The same syllabus that has been used in the past was used. Every class focussed on unique topics and the active learning activities were taken directly from the topics that were taught from the specific lecture on that day. That way there were no topics taught over several days. The syllabus is included in Appendix 1.

Active learning activities: Our lecture hall held 220 people. We had 170 students in the class. The students were already broken into 6 recitation sections with about 28-29 students in each. We asked the students to sit with their section on Wednesdays so that the Graduate Student Instructor (GSI) that was assigned to their section could help them with the active learning methods. The GSI took attendance, helped provoke discussion and participation, answered questions, and help guide the students when they noticed they were going in the wrong direction or were using incorrect assumptions or methods. 
Several active engagement methods were used on Wednesdays. We used standard active learning techniques that have been widely published, discussed, and suggested by our Center for Research on Learning and Teaching through their resources on active learning ${ }^{2}$. Many of the activities were created by the author, but he recognizes that others may have come up with similar methods previously and he takes no credit for them. The Think-Pair-Share and peer instruction techniques elucidated by Eric Mazur ${ }^{3}$ were the most commonly used method. Because we were in a large lecture hall, we had to create small groups of 3-4 people that were sitting close to each other. We engaged the groups by putting questions on the large screen in front of the class and asking them to solve the problems that were posed. Our typical workflow involved abstracting the concepts, derivations and examples that we would have used in lecture, and turned them into guided inquiry problems by breaking them up into small parts and asking the groups to take things one step at at time. For example, we asked each group to write down the derivation of Bragg's law by producing a drawing. We collected the drawings and then showed a random sample of them to the class using an aural histogram (the students clapped for the ones that were correct). We also simply had students use a piece of paper to draw a graph of the data they calculated. The learning objectives that had been written down previously actually matched our activities very well.

Dominant Active Learning Activity: Most of the active learning activities were centered around homework and example problems to make sure we covered every learning objective in each class. The problems were broken down into discrete steps and then each step was used as a peer learning activity. For example, we used the following process:

Step 1: Write down all of the information the problem is providing, draw a picture that represents the problem and write down what the problem is asking you to find

Step 2: Identify any assumptions that need to be made (if any) to approach the problem/ and or think about whether or not you need to break the problem into parts

Step 3: Identify the concepts and related equations that would be useful to solve this problem

Step 4: Solve the problem

Step 5: Check the reasonableness of the solution

Step 6: Draw the solution if applicable.

Each step emphasizes classic problem solving approaches and permits an excellent opportunity to walk a student through a problem. Students were asked to (1) first work on the step 
themselves, then (2) compare their answers to the students nearby (3) then, if they had different answers, they would then defend their solutions during a short discussion.

We did not use any clickers or other technology. We asked them to hold up their results so that the GSIs and the instructor could get a sense if they were getting the right answer or not.

This was followed by a (very) short presentation of what the instructor would have done using a Keynote slide presentation.

Demonstrations: We used the demonstrations that were typically planned for that part of the syllabus as a method of group inquiry. We either asked the groups to predict what would happen in our demonstration, or we asked them the explain why we observed the phenomenon that just occurred. For example, to demonstrate the bcc to fcc phase transformation in pure iron upon heating or cooling we had fixed a length of piano wire (very low carbon steel) to two posts. Passing ac current through it with a Variac heated it resistively. We first asked the student to predict what would happen. Then we did the experiment and asked them to explain what they observed (first the wire sagged, then tightened, then sagged again upon heating, then did the opposite upon cooling).

Additional active learning methods included playing a game of Jeopardy, having groups draw 3 or 4 panel storyboards of the way they were going to explain a concept to a high school student, online clicker questions and other guided learning activities.

Pre-work: Because we were not lecturing, we needed to have the students prepare for the class by reading the textbook. We chose not to make them watch a video of a lecture because we felt that such a presentation is actually worse than a live lecture. The problem we faced was how did we motivate the students to read the book. The approach that was implemented consisted of 3 distinct components.

(1) We discussed the approach with the student using a written document, a short introductory video and by talking to them the first day of class. These communications were focussed on the value of reading a book, the acquisition of the life-long learning skill of learning on your own, and the fact that they would not have to waste time in a boring lecture.

(2) Short online quizzes were prepared that the students had to take before coming to class. These quizzes consisted of 5 questions that were drawn randomly from a pool of 12 to 15 problems each week. The problems were either multiple choice, many choice, fill in the blank, or numerical questions. The quizzes were worth $10 \%$ of the course grade and the 
students received their score as soon as they submitted their answers. We allowed the students to retake the quiz as many times as they wanted until they got the score they were satisfied with. Most students ended up cycling through the entire pool of questions each week. While this did not force the students to read the entire chapter, at least it helped them read the parts of the book that we thought were the most important by our choice of question. Typical questions are listed below:

1) To improve the lifetime of a part that experiences fatigue you can:

A. Paint the surface

B. Lower the mean stress

C. Decrease the size of the part

D. Introduce sharp corners

2) Cracks usually grow faster as loading frequency increases, decreases). (stays the same,

3) Silicon is doped with atoms having 5 valence electrons. This creates a type semiconductor.

4) The conductivity of Si doped with $10^{24}$ Boron atoms per cubic meter at room temperature ( 25 degrees $\mathrm{C}$ ) is $\left(\mathrm{Ohms}{ }^{*} \mathrm{~m}\right)^{-1}$. Give your answer with two significant figures and use a format for exponential notation as follows: $34 \mathrm{E}-23$.

(3) One aspect of lecture that we thought was valuable was the value of an inspirational lecturer. It is well know that Richard Feynman's lectures were engaging and inspirational. Yet, most people, if asked right after watching one of his lectures, would not be able to tell you what physics he actually explained. Yet, after watching one of his lectures, many people, myself included, ran out and bought his lecture notes which were amazing. While we will never be nearly as inspirational as Richard Feynman, most faculty are able to and strive to inspire students to want to read the book and study while they lecture. To replace this component of the lecture we turned to video. Film is a medium that excels at inspiration and evoking emotion. Since the course was a survey course, a single instructor would rarely have the depth across all of the topics covered in the term. So, we found a World class expert for each of the 13 areas of Materials Science and Engineering that were covered on each of the 13 Wednesdays. We filmed interview with the faculty expert as well as with her or his graduate students. We also filmed "B-roll" of their labs to put in front of the interviews to make the videos more visually interesting. The intent of all of the interviews was to capture the 
passion that the researchers had for the topics and to show that the topics were so compelling, that it was easily worth 10 hours of the students' time to master the subject. These videos can be found at the website for the 2013 version of the course (another story for another paper) http://java.engin.umich.edu/220f13/page21/index.html .

Other aspects of the course remained constant. Each week was a GSI led recitation which included a short closed book quiz, short lecture and homework review. The students were also given two midterm exams and a final that were very similar to previous years treatments.

\section{Measurement instrument}

All three exams in the course covered the material evenly across the course. The two midterm exams only covered material in the 4 to 6 weeks prior to the exam and were not cumulative. The final exam was cumulative and covered the material in the course evenly with a $10 \%$ extra coverage for the last four weeks of the course. Our metric for student learning was the score they received on exam questions. Because we wrote the exam based strictly on the learning objectives, we were able to tag questions based on which type of class instruction was first used to introduce them. Hence, we broke up each exam into questions that were taught in a lecture environment and those that were taught in an active learning environment. We collected the scores, normalized them to $100 \%$, plotted the distributions and calculated the median scores of the two sets of questions, lecture based (Mondays and Fridays) and active learning based (Wednesdays). 


\section{Results}

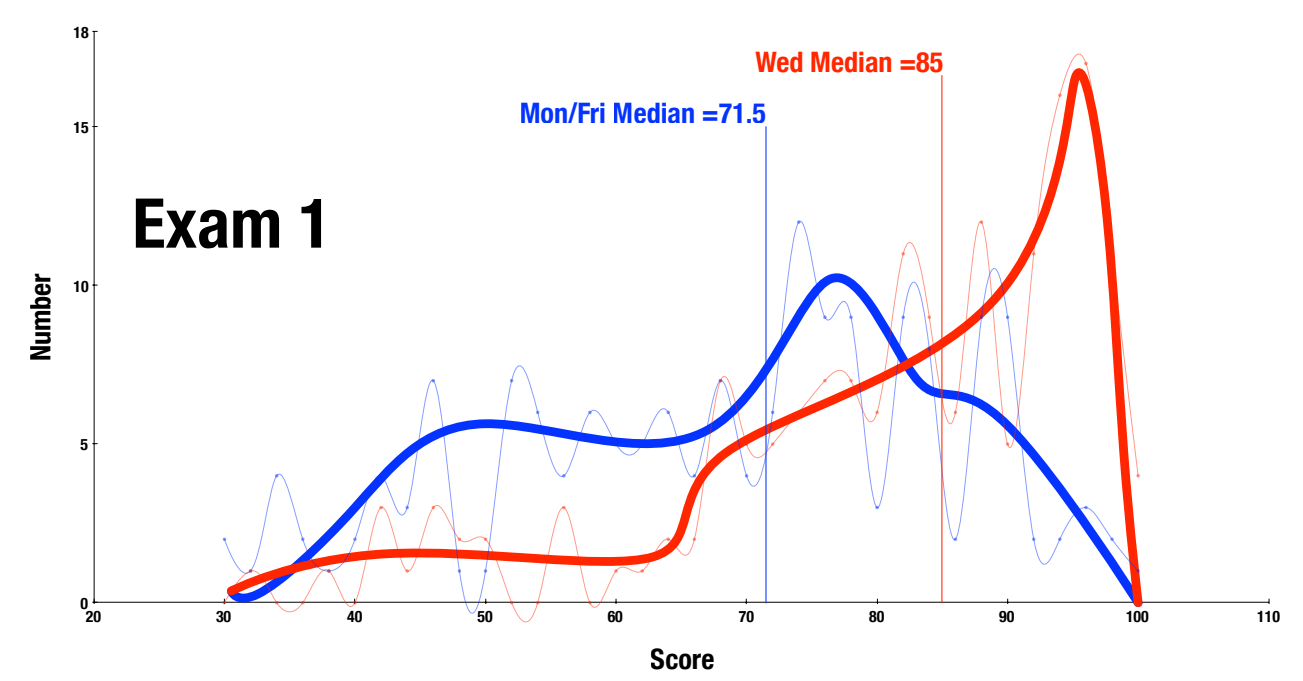

Figure 1 shows the data collected from the first midterm. The data in blue are from questions based on a lecture environment and those in red are from the active learning environment. The raw data is represented by the dots with light lines connecting them. The dark lines are drawn by hand to aid the eye.

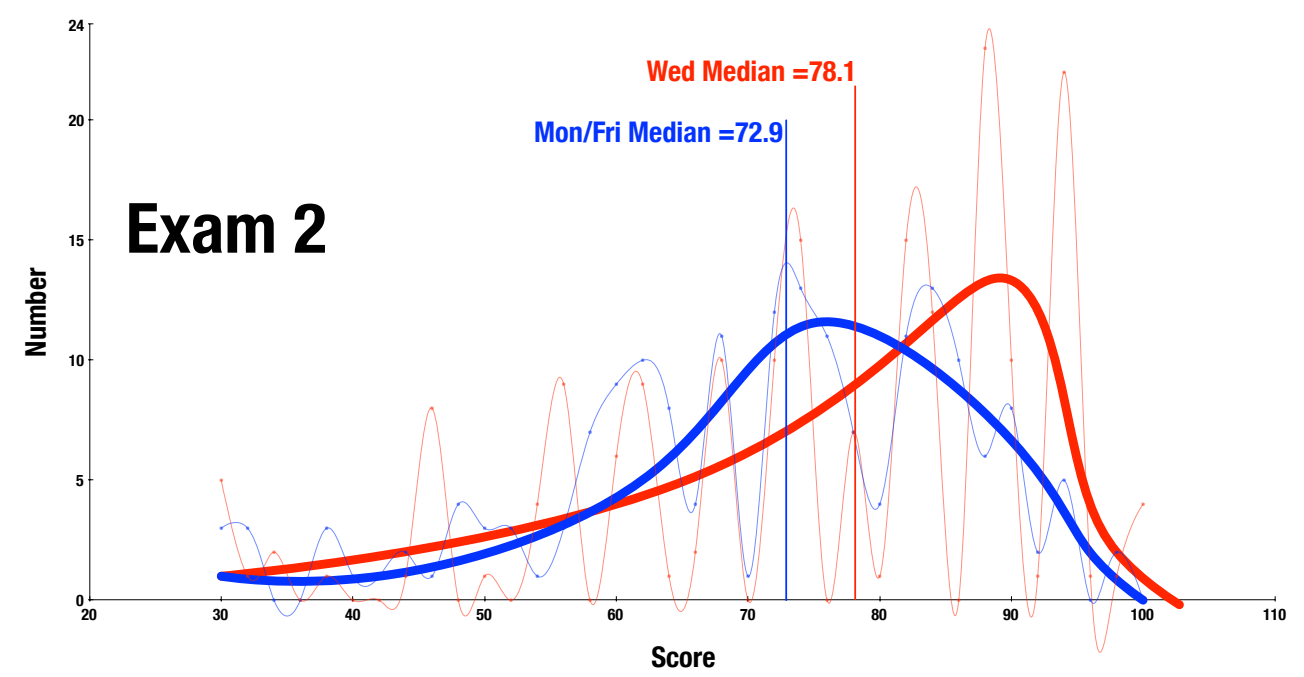

Figure 2 shows the data collected from the second midterm exam. The data in blue are from questions based on a lecture environment and those in red are from the active learning environment. The raw data is represented by the dots with light lines connecting them. The dark lines are drawn by hand to aid the eye. 


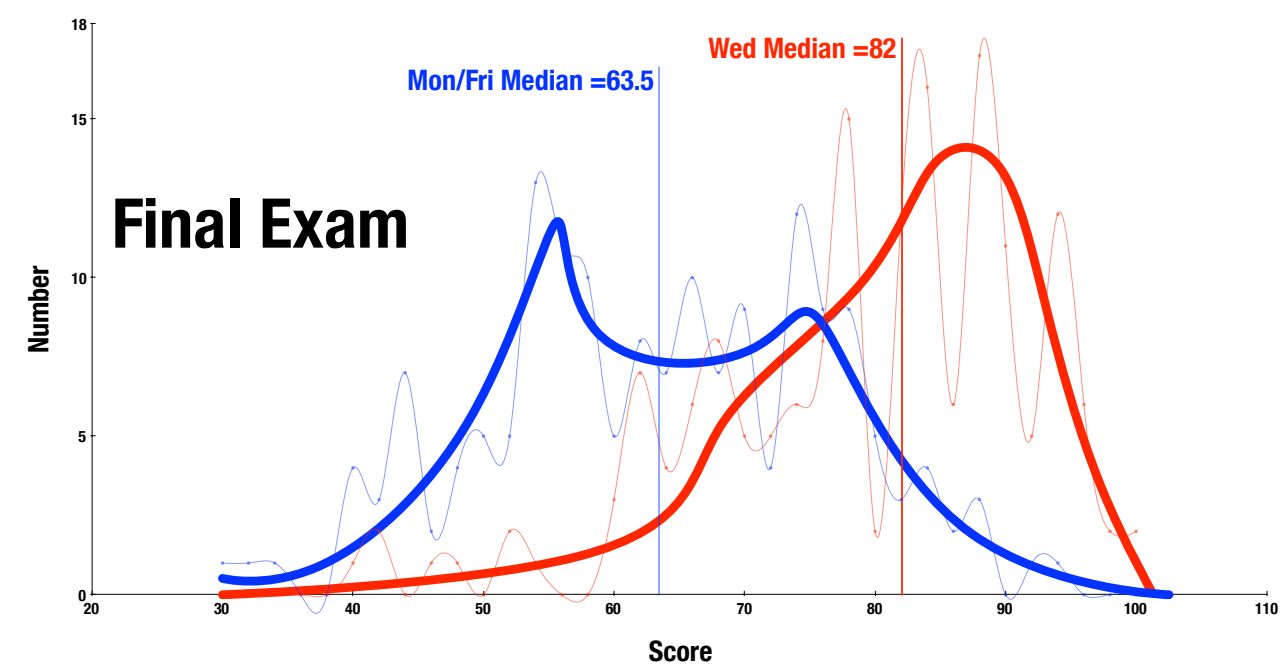

Figure 3 shows the data collected from the cumulative final exam. The data in blue are from questions based on a lecture environment and those in red are from the active learning environment. The raw data is represented by the dots with light lines connecting them. The dark lines are drawn by hand to aid the eye.

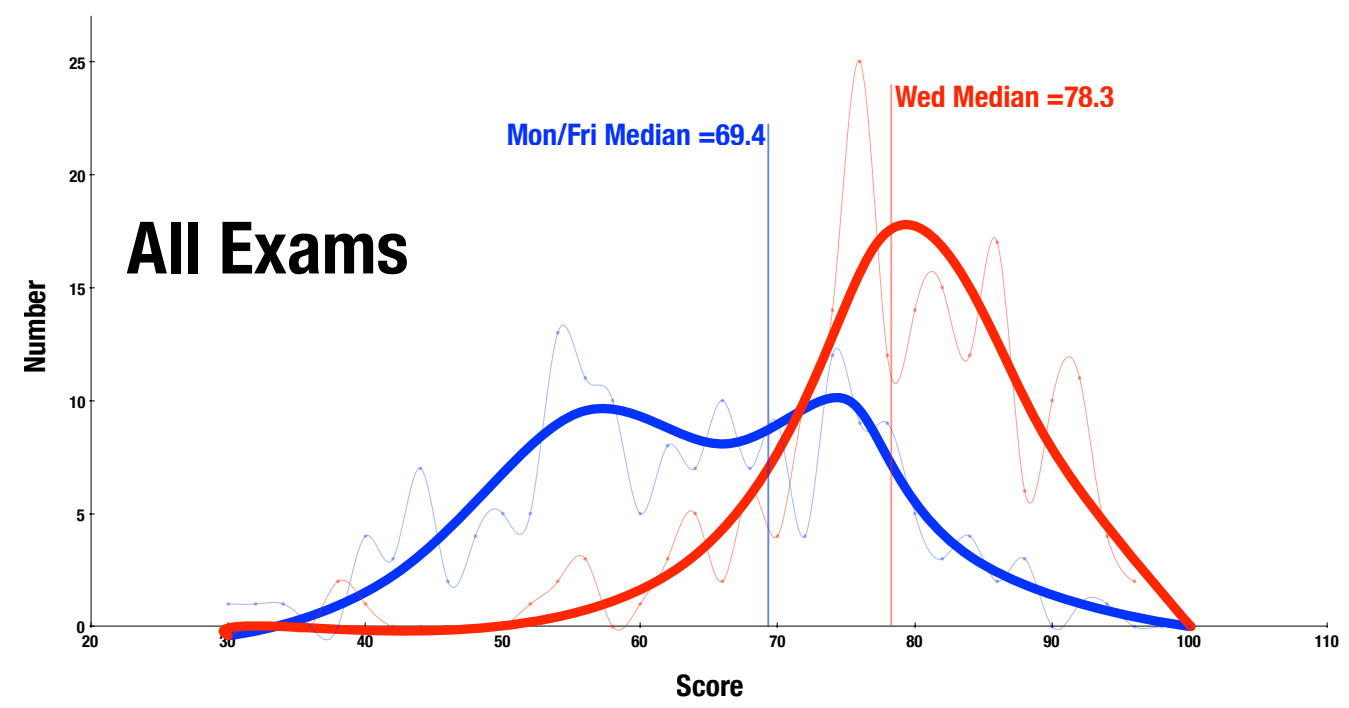

Figure 4 shows the data averaged over all three exams. The data in blue are from questions based on a lecture environment and those in red are from the active learning environment. The raw data is represented by the dots with light lines connecting them. The dark lines are drawn by hand to aid the eye. 


\section{Discussion}

The data show that there are clear gains in student scores on exam questions when active learning methods are used as a replacement for lecture. What is most interesting is the result from the final exam which shows the largest gain. These data are consistent with an enhancement in retention of knowledge. There was no attempt to measure other variables such as the role of gender, time of day of lecture, whether Mondays or Fridays were better or worse days to expect students to be attentive compared to Wednesdays or any other variables. The data have convinced the authors that lecture should be avoided, if possible, in favor of active learning activities.

\section{Conclusion}

Data was collected to assess the role of the pedagogical approach by tagging questions that were based on traditional lecture (blue) or on the active learning sessions (red). The figures above show that the distribution of the scores significantly improved in all exams. The final exam showed that the median shifted about 19 points for those questions that were based on the active learning sessions.

${ }^{1}$ Michael Prince ,Does Active Learning Work? A Review of the Research, Journal of Engineering Education, July 2004.

${ }^{2}$ http://www.crlt.umich.edu/sites/default/files/resource files/Active\%20Learning\%20Continuum.pdf.

${ }^{3}$ Eric Mazur, Peer Instruction: A User's Manual, Prentice Hall, 1997. 
Appendix 1: Syllabus for the Course

\begin{tabular}{|c|c|c|c|c|}
\hline Wk & Lecture & Date & Lecture and Reading Assignment & $\begin{array}{l}\text { Homework (due on } \\
\text { date shown) }\end{array}$ \\
\hline \multirow[t]{2}{*}{1} & 1 & Sep. 5 & $\begin{array}{l}\text { Course Organization and Intro, 1.1- } \\
1.6\end{array}$ & \\
\hline & 2 & Sep. 7 & Atomic Bonding, 2, 19.3 & \\
\hline \multirow[t]{3}{*}{2} & 3 & Sep. 10 & Structure, 3.1-7 & \\
\hline & 4 & Sep. 12 & Crystallography, 3.8-3.17 & \\
\hline & 5 & Sep. 14 & Point Defects, 4.1-4.4 & $\begin{array}{l}\text { HW1 } \\
2.14,2.16,2.20,2.23, \\
19.13,3.6,3.15,3.17\end{array}$ \\
\hline \multirow[t]{3}{*}{3} & 6 & Sep. 17 & Line and Planar Defects, 4.5-4.11 & \\
\hline & 7 & Sep. 19 & Diffusion, 5.1-5.3, 5.5 & \\
\hline & 8 & Sep. 21 & $\begin{array}{l}\text { Non-Steady State Diffusion, } 5.4 \text { - } \\
5.7\end{array}$ & $\begin{array}{l}\text { HW2 } \\
3.30 \mathrm{a}-c, 3.31,3.40 \mathrm{a}-\mathrm{c}, \\
3.41,4.2,4.5,4.20, \\
4.28\end{array}$ \\
\hline \multirow[t]{3}{*}{4} & 9 & Sep. 24 & $\begin{array}{l}\text { Mechanical Properties - Elastic, } \\
6.1-6.5\end{array}$ & \\
\hline & 10 & Sep. 26 & $\begin{array}{l}\text { Mechanical Properties - Plastic, } \\
6.6-6.12\end{array}$ & \\
\hline & 11 & Sep. 28 & Deformation, 7.1-7.6 & $\begin{array}{l}\text { HW3 } \\
5.3,5.7,5.13,5.15 \\
5.21,5 . D 3,6.7,6.18\end{array}$ \\
\hline \multirow[t]{3}{*}{5} & 12 & Oct. 1 & $\begin{array}{l}\text { Strengthening, } 7.8-7.10 \text { (last } \\
\text { reading for Exam1) }\end{array}$ & \\
\hline & 13 & Oct. 3 & Recovery, 7.11-7.13 & \\
\hline & 14 & Oct. 5 & Failure, $8.1-8.6$ & $\begin{array}{l}\text { HW4 } \\
6.26,6.28,6.43,6.51 \text {, } \\
6 D 1,7.1,7.14,7.28 \\
\text { (last homework for } \\
\text { Exam 1) }\end{array}$ \\
\hline \multirow[t]{3}{*}{6} & 15 & Oct. 8 & Fatigue and Creep 8.7-8.13 & \\
\hline & 16 & Oct. 10 & $\begin{array}{l}\text { Fatigue and Creep continued, and } \\
\text { Review }\end{array}$ & \\
\hline & 17 & Oct. 12 & Exam 1 & $\begin{array}{l}\text { HW5 } \\
7.32,7 . D 2,8.2,8.6, \\
8.15,8.21\end{array}$ \\
\hline \multirow[t]{3}{*}{7} & & Oct. 15 & No class: Fall Break & \\
\hline & 18 & Oct. 17 & Phase Diagrams, 9.1-9.6 & \\
\hline & 19 & Oct. 19 & Binary Phase Diagrams, 9.7-9.15 & $\begin{array}{l}\text { HW6 } \\
8.31,8.32,8.35,8 . D 4, \\
9.1,9.11\end{array}$ \\
\hline \multirow[t]{3}{*}{8} & 20 & Oct. 22 & Binary Phase Diagrams, 9.17-9.20 & \\
\hline & 21 & Oct. 24 & Phase Transformations, 10.1-4 & \\
\hline & 22 & Oct. 26 & $\begin{array}{l}\text { Microstructure/Properties, 10.5- } \\
10.9\end{array}$ & $\begin{array}{l}\text { HW7 } \\
9.20,9.33,9.36,9.45, \\
9.53,9.58\end{array}$ \\
\hline
\end{tabular}

\begin{tabular}{|c|c|c|c|c|}
\hline Wk & Lecture & Date & Lecture and Reading Assignment & $\begin{array}{l}\text { Homework (due on } \\
\text { date shown) }\end{array}$ \\
\hline \multirow[t]{3}{*}{9} & 23 & Oct. 29 & $\begin{array}{l}\text { Metal alloys and processing, 11.1- } \\
11.9\end{array}$ & \\
\hline & 24 & Oct. 31 & Ceramics, 12.1-12.4 & \\
\hline & 25 & Nov. 2 & Ceramic Structure, 12.5-12.11 & $\begin{array}{l}\text { HW8 } \\
10.4,10.14,10.18 \\
10.20,10.24,11.13 \\
11.15,11 . D 1\end{array}$ \\
\hline \multirow[t]{3}{*}{10} & 26 & Nov. 5 & $\begin{array}{l}\text { Ceramic Processing, 13.1-13.3, 13.5, } \\
\text { 13.8,13.9, 13.11(last reading for } \\
\text { Exam 2) }\end{array}$ & \\
\hline & 27 & Nov. 7 & Polymer Basics, 14.1-14.6 & \\
\hline & 28 & Nov. 9 & Polymer Structure, 14.7-14.14 & $\begin{array}{l}\text { HW9 } \\
\text { 11.D14, 12.5, 12.11, } \\
\text { 12.27, 12.30, 12.39, } \\
\text { 13.10, 13.15 (last } \\
\text { homework for Exam 2) }\end{array}$ \\
\hline \multirow[t]{3}{*}{11} & 29 & Nov. 12 & $\begin{array}{l}\text { Mechanical Properties of Polymers, } \\
15.1-15.9\end{array}$ & \\
\hline & 30 & Nov. 14 & $\begin{array}{l}\text { Mechanical Properties of Polymers, } \\
15.10-15.19 \text { and review }\end{array}$ & \\
\hline & 31 & Nov. 16 & Exam 2 & $\begin{array}{l}\text { HW10 } \\
14.1,14.6,14.9,14.14 \\
14.17,14.23\end{array}$ \\
\hline \multirow[t]{3}{*}{12} & 32 & Nov. 19 & Polymer Processing, 15.20-15.24 & \\
\hline & 33 & Nov. 21 & Composites, $16.1-5$ & \\
\hline & & Nov. 23 & No Class, Thanksgiving & \\
\hline \multirow[t]{3}{*}{13} & 34 & Nov. 26 & Composites, $16.6-16.15$ & $\begin{array}{l}\text { HW11 } \\
15.6,15.32,15.34\end{array}$ \\
\hline & 35 & Nov. 28 & Corrosion, 17.1-13 & \\
\hline & 36 & Nov. 30 & $\begin{array}{l}\text { Electrical conduction in Metals, } \\
18.1-9\end{array}$ & $\begin{array}{l}\text { HW12 } \\
16.3,16.8,16.13,16 . D 3\end{array}$ \\
\hline \multirow[t]{3}{*}{14} & 37 & Dec. 3 & Semiconductivity, 18.10 & \\
\hline & 38 & Dec. 5 & Semiconductivity, 18.11-18.14 & \\
\hline & 39 & Dec. 7 & Electronic devices, 18.15-18.17 & \\
\hline \multirow[t]{2}{*}{15} & 40 & Dec. 10 & $\begin{array}{l}\text { Case study of Turbine Disc Design } \\
\text { against failure }\end{array}$ & $\begin{array}{l}\text { HW13 } \\
17.5,17.13,17.19,18.1, \\
18.11,18.21,18.30 \\
18.33\end{array}$ \\
\hline & & Dec. 14 & Final Exam 4:00 PM-6:00 PM & \\
\hline
\end{tabular}

